\title{
Evaluation of Antiemetic Therapy for Hepatic Transcatheter Arterial Infusion Chemotherapy with Cisplatin
}

\author{
Junya Hashizume, Norihide Higuchi,* Kayoko Sato, Yukinobu Kodama, Noriko Matsunaga, \\ Toshiaki Sakamoto, Kentaro Yamaguchi, Tadahiro Nakamura, Takashi Kitahara, and \\ Hitoshi Sasaki
}

Department of Hospital Pharmacy, Nagasaki University Hospital; 1-7-1 Sakamoto, Nagasaki 852-8501, Japan. Received July 30, 2015; accepted January 5, 2016

Antiemetic prophylaxis with aprepitant, a 5-hydroxytryptamine ${ }_{3}\left(5-\mathrm{HT}_{3}\right)$ receptor antagonist and dexamethasone is recommended for patients receiving intravenous cisplatin chemotherapy. Whether the same antiemetic regime is superior for hepatic transcatheter arterial infusion chemotherapy with cisplatin (CDDP-TAI) is unknown. We conducted a retrospective study of antiemetic prophylaxis protection against chemotherapy-induced nausea and vomiting (CINV) in CDDP-TAI at Nagasaki University Hospital. The rate of complete response $(\mathrm{CR})$ to antiemetics in the acute $(<24 \mathrm{~h})$ and delayed phases $(24-120 \mathrm{~h})$ was measured. Twenty-four patients were treated with a $5-\mathrm{HT}_{3}$ receptor antagonist (granisetron or azasetron) and dexamethasone on the day of chemotherapy (day 1 only). There was a significant difference between the CR rates in the acute and delayed phases, 91.6 , and $69.7 \%$, respectively. Combination of a 5-HT 3 antagonist and dexamethasone on day 1 is effective against acute CINV, but not delayed CINV during CDDP-TAI. These results may help guide the management of nausea and vomiting during CDDP-TAI to achieve better tolerance and compliance for fewer interventions and increased favorable therapeutic outcomes.

Key words antiemetic; cisplatin; 5-hydroxytryptamine ${ }_{3}\left(5-\mathrm{HT}_{3}\right)$ receptor antagonist; transcatheter infusion chemotherapy

Chemotherapy-induced nausea and vomiting (CINV) is an adverse event that can last for days following therapy and can significantly impair a patient's quality of life. Patients developing CINV may occasionally be forced to discontinue or postpone their chemotherapy. ${ }^{1)}$ Thus, it is crucial to provide appropriate supportive care for the continuity of chemotherapy. CINV is classified into acute CINV (occurring within $24 \mathrm{~h}$ of chemotherapy) and delayed CINV (occurring more than $24 \mathrm{~h}$ after chemotherapy).

cis-Diamminedichloroplatinum(II) (CDDP; cisplatin) possesses a high risk of inducing CINV according to the emetogenic classification schema. CDDP is administered intravenously or intra-arterially. The antiemetic guidelines of the Multinational Association for Supportive Care in Cancer (MASCC), ${ }^{2)}$ the National Comprehensive Cancer Network (NCCN), ${ }^{3)}$ the American Society of Clinical Oncology $(\mathrm{ASCO})^{4)}$ and the Japanese Society of Clinical Oncology $(\mathrm{JSCO})^{5)}$ recommend a three-drug combination with aprepitant (days 1-3), a 5-hydroxytryptamine ${ }_{3}\left(5-\mathrm{HT}_{3}\right)$ receptor antagonist (5- $\mathrm{HT}_{3}$ antagonist) (day 1) and dexamethasone (days 1-3 or 1-4). However, intra-arterial administration of CDDP appears to be more effective than intravenous (i.v.) administration for the treatment of hepatocellular carcinoma. The concentration of CDDP in hepatocyte of intra-arterial administration is higher than i.v. administrarion. ${ }^{6)}$ Thus, intra-arterial administration of CDDP is thought to have fewer systemic adverse effects than i.v. administration. ${ }^{7)}$ However, Louvet et al. reported that CINV was observed immediately following a high-dose, CDDP liver arterial injection. ${ }^{8)}$ Furthermore, despite receiving $5-\mathrm{HT}_{3}$ receptor antagonist prophylaxis, patients in a phase II study of transcatheter arterial infusion chemotherapy with CDDP (CDDP-TAI) experienced anorexia and vomiting at rates of 82.5 and $40.0 \%$, respectively. ${ }^{9)}$ Thus, a
5- $\mathrm{HT}_{3}$ receptor antagonist alone may be insufficient antiemetic prophylaxis for CDDP-TAI. More research is required to establish antiemetic prophylaxis guidelines for CDDP-TAI.

In the present study, we retrospectively investigated the effectiveness of antiemetic therapy regimes for CDDP-TAI across acute and delayed phases of CINV.

\section{PATIENTS AND METHODS}

Patients This study was carried out in accordance with the Declaration of Helsinki (Fourth revision: Somerset West, South Africa, 1996) and under approval by the Nagasaki University Ethics Committee (No. 14052666). Subjects comprised 33 patients who received a first course of CDDP-TAI for hepatocellular cancer at the Nagasaki University Hospital from April 2009 to September 2013. Patients were excluded from

\section{Table 1. Patients Characteristics}

\begin{tabular}{lc}
\hline \hline & Patients $(n=33)$ \\
\hline Sex (male/female) & $26 / 7$ \\
History of alcohol intake (yes/no) & $9 / 24$ \\
History of CINV (yes/no) & $3 / 30$ \\
Combination of anticancer agents (yes/no) & $18 / 15$ \\
\hline & Median (range) \\
\hline Age (years) & $61(31-84)$ \\
Weight $(\mathrm{kg})$ & $59.0(40.6-88.9)$ \\
Body surface area $\left(\mathrm{m}^{2}\right)$ & $1.63(1.31-2.01)$ \\
Dose of intra-arterial of cisplatin $\left(\mathrm{mg} / \mathrm{m}^{2}\right)$ & $55.9(34.0-76.3)$ \\
Serum creatinine $(\mathrm{mg} / \mathrm{dL})$ & $0.73(0.48-1.27)$ \\
Creatinine clearance ${ }^{a}(\mathrm{~mL} / \mathrm{min})$ & $77.6(48.2-174.6)$ \\
\hline
\end{tabular}

a) Cockcroft-Galut calculation. 
this study because of either complications that induced nausea and/or vomiting (e.g. symptomatic brain metastases, opioid dose change within $120 \mathrm{~h}$ following chemotherapy), or the use of corticosteroids for reasons other than antiemesis. Baseline characteristics of included patients are presented in Table 1.

Treatment Schedule The fine-powder formation of CDDP was completely dissolved in $70 \mathrm{~mL}$ saline and heated to $50^{\circ} \mathrm{C}$. A catheter was introduced into the hepatic artery under angiographic guidance, and CDDP was administrated at a dose of $40-65 \mathrm{mg} / \mathrm{m}^{2}$ by infusion into the artery. Adequate hydration was administrated before and after CDDP-TAI by an i.v. infusion of $1000-2000 \mathrm{~mL}$ to prevent kidney damage. Some patients were received antiemetic prophylaxis before CDDP-TAI on day 1 . When patients were received antiemetic prophylaxis on days 2 and 3, aprepitant or dexamethasone was orally administrated in the morning.

Data Collection and Assessment All data were retrospectively collected from the electronic medical record system. They included age, sex, weight, body surface area, history of alcohol intake, dose of CDDP, history and episodes of CINV, and whether other anticancer agents and antiemetic agents were also used. The primary measured endpoint was determined as the achievement of a complete response (CR) to antiemetics in which there were no emetic episodes and no administration of rescue therapy within $120 \mathrm{~h}$ after the start of chemotherapy. ${ }^{2)}$ This endpoint was further classified into an acute phase (within the first $24 \mathrm{~h}$ ) and a delayed phase (24-120 h).

Statistical Analysis McNemar's test was used to compare the CR rates between the acute phase, delayed phase and overall phase. Comparisons of $\mathrm{CR}$ rates among $5-\mathrm{HT}_{3}$ receptor antagonists were analyzed using the Yates' chi-squared test. Data were analyzed using Microsoft Excel 2010, and a $p$ value of $<0.05$ was considered statistically significant.

\section{RESULTS}

Antiemetic Therapies for CDDP-TAI CINV The antiemetic therapy regimes used for CINV during this study are detailed in Table 2. Three patients were not treated with any antiemetic and two patients were treated with i.v. granisetron
$3 \mathrm{mg}$ (day 1 only). Twenty-four patients were treated with an i.v. $5-\mathrm{HT}_{3}$ receptor antagonist and dexamethasone $8 \mathrm{mg}$ on day 1 only. $5-\mathrm{HT}_{3}$ receptor antagonists included azasetron $10 \mathrm{mg}$ $(n=7)$, granisetron $1 \mathrm{mg}(n=10)$ and granisetron $3 \mathrm{mg}(n=7)$. Three patients were treated with i.v. granisetron 1 or $3 \mathrm{mg}$, and dexamethasone 8 or $13.2 \mathrm{mg}$ on day 1 , followed by oral dexamethasone 4 or $8 \mathrm{mg}$ on days 2 and 3. One patient was given oral aprepitant $125 \mathrm{mg}$, i.v. palonosetron $0.75 \mathrm{mg}$ and dexamethasone $4 \mathrm{mg}$ on day 1 , followed by oral aprepitant $80 \mathrm{mg}$ on days 2 and 3.

Efficacy CR rates in the acute phase and delayed phase for all patients were 87.9 and $69.7 \%$, respectively (Fig. 1). Further, the CR rate in the delayed phase was significantly lower than that in the acute phase for all patients $(p=0.031)$. $\mathrm{CR}$ rates in the acute phase and delayed phase for twentyfour patients, received with a $5-\mathrm{HT}_{3}$ receptor antagonist and dexamethasone $8 \mathrm{mg}$ on day 1 only, were 91.7 and $66.7 \%$, respectively. Similarly, the $\mathrm{CR}$ rate in the delayed phase was significantly lower than that in the acute phase $(p=0.031)$. Further, the CR rates in the acute phase for azasetron $10 \mathrm{mg}$, granisetron $1 \mathrm{mg}$, and granisetron $3 \mathrm{mg}$ were 100, 85.7, and $90.0 \%$, respectively, and in the delayed phase were $71.4,57.1$, and $70.0 \%$, respectively. There were no significant differences between the CR rates in the acute phase and in the delayed phase between azasetron $10 \mathrm{mg}$, granisetron $1 \mathrm{mg}$ and granisetron $3 \mathrm{mg}$ (Table 3). Both CR rates in the acute phase and the delayed phase for the three patients who were not treated with any antiemetic were $33.3 \%$. Both CR rates in the acute phase and the delayed phase for three patients treated with granisetron 1 or $3 \mathrm{mg}$, and dexamethasone 8 or $13.2 \mathrm{mg}$ on day 1 , followed by dexamethasone 4 or $8 \mathrm{mg}$ on days 2 and 3, were $100 \%$. A similar CR rate was seen for one patient was given aprepitant $125 \mathrm{mg}$, palonosetron $0.75 \mathrm{mg}$ and dexamethasone $4 \mathrm{mg}$ on day 1 , followed by oral aprepitant $80 \mathrm{mg}$ on days 2 and 3. The CR rates in the acute and delayed phase for two patients receiving granisetron $3 \mathrm{mg}$ on day 1 only were also $100.0 \%$ (data not shown).

\section{DISCUSSION}

Since the first-generation $5-\mathrm{HT}_{3}$ receptor antagonist granis-

Table 2. Antiemetic Regimes

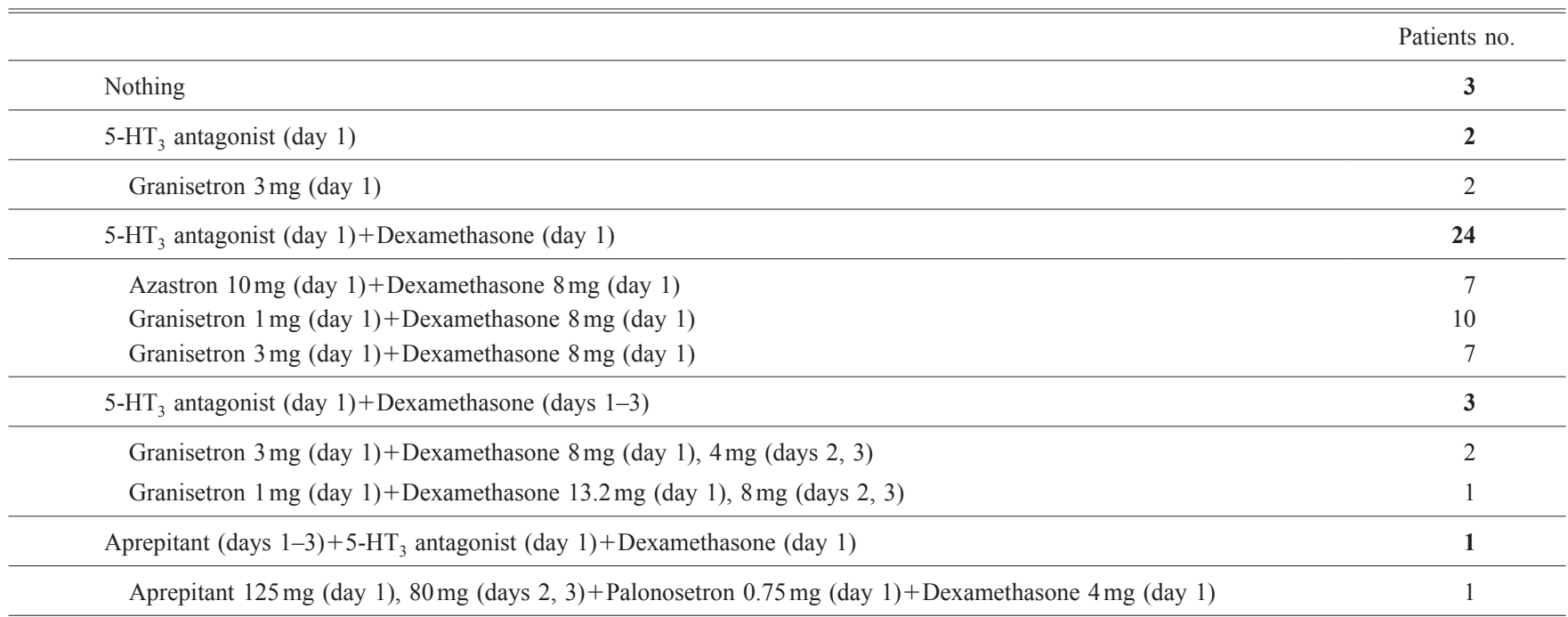




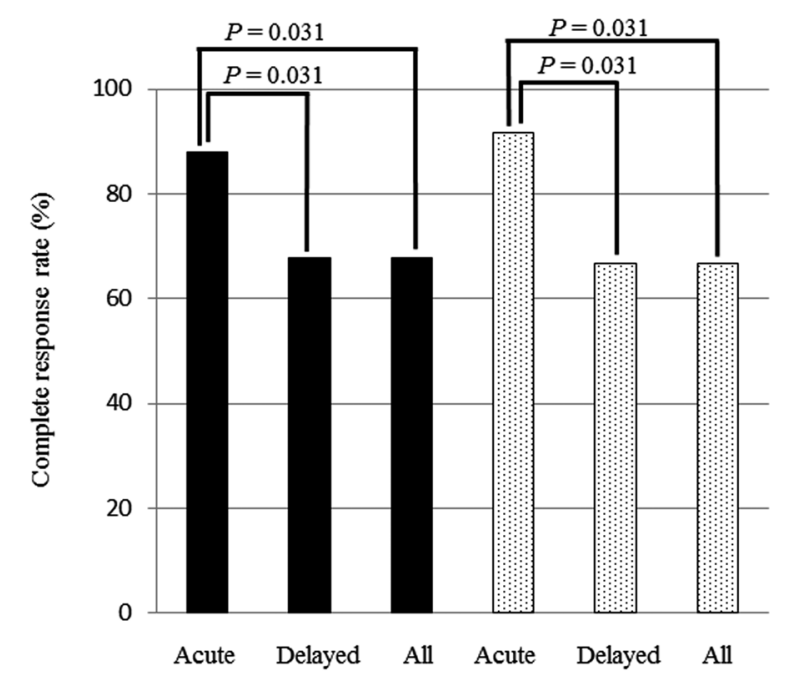

All patients $(\mathrm{n}=33)$

Patients administrated 5- $\mathrm{HT}_{3}$ receptor antagonist and dexamethasone on day $1(\mathrm{n}=24)$

Fig. 1. Complete Response Rates Sorted According to Antiemetic Regime and Acute, Delayed or Combined Phases

Statistical differences determined using McNemar's test.

Table 3. Comparison of Complete Response Rates of Azasetron $10 \mathrm{mg}$, Granisetron $1 \mathrm{mg}$ and Granisetron $3 \mathrm{mg}$

\begin{tabular}{|c|c|c|c|c|c|c|c|}
\hline & \multicolumn{7}{|c|}{ Complete response } \\
\hline & \multicolumn{2}{|c|}{ Azasetron $10 \mathrm{mg}$} & \multicolumn{2}{|c|}{ Granisetron $3 \mathrm{mg}$} & \multicolumn{2}{|c|}{ Granisetron $1 \mathrm{mg}$} & \multirow{2}{*}{$p$ Value } \\
\hline & Rate & Individuals (CR/overall) & Rate & Individuals (CR/overall) & Rate & Individuals (CR/overall) & \\
\hline Acute phase & 100.0 & $7 / 7$ & 85.7 & $6 / 7$ & 90.0 & $9 / 10$ & 0.918 \\
\hline Delayed phase & 71.4 & $5 / 7$ & 57.1 & $4 / 7$ & 70.0 & $7 / 10$ & 0.976 \\
\hline All phases & 71.4 & $5 / 7$ & 57.1 & $4 / 7$ & 70.0 & $7 / 10$ & 0.976 \\
\hline
\end{tabular}

etron was marketed in the early $1990 \mathrm{~s}$, this pharmacological class has played a central role in the antiemetic therapy for CINV. While granisetron was shown to mitigate acute CINV, its efficacy for delayed CINV is limited. ${ }^{10)}$ Conversely, the more recently developed aprepitant, a selective neurokinin-1 receptor antagonist, ${ }^{11-13)}$ and palonosetron, a long-acting second-generation $5-\mathrm{HT}_{3}$ receptor antagonist, ${ }^{14)}$ have demonstrated promising outcomes in the control of delayed CINV. While antiemetic guidelines published in Japan, U.S.A. and Europe should be used to determine the risk of emesis in CINV, ${ }^{2-5)}$ the guidelines were not written for CDDP-TAI CINV prophylaxis. To address this problem, we have investigated antiemetic therapies for CDDP-TAI.

The important finding was that the $\mathrm{CR}$ rate in the delayed phase was significantly lower than in the acute phase for the group receiving a $5-\mathrm{HT}_{3}$ receptor antagonist and dexamethasone on day 1 only. However, there were no significant differences amongst the different $5-\mathrm{HT}_{3}$ receptor antagonist treatments (namely, azasetron $10 \mathrm{mg}$, granisetron $1 \mathrm{mg}$ and granisetron $3 \mathrm{mg}$ ) (Table 3 ). This result is in accord with other reports that azasetron is not inferior to granisetron, ${ }^{15}$ and that there are no significant differences between 1- and 3-mg granisetron. ${ }^{16-18)}$ Matsumura et al. reported that patients treated with granisetron $40 \mu \mathrm{g} / \mathrm{kg}$ and dexamethasone $8 \mathrm{mg}$ before CDDP-TAI experienced reduced food intake from days 1 to 8 and a loss of appetite from days 1 to $2 .{ }^{19)}$ From this observation, and from the results in the present study, the delayed phase of CINV following CDDP-TAI does not appear to be adequately controlled by a $5-\mathrm{HT}_{3}$ receptor antagonist and 8-mg dexamethasone on day 1 only.

Aprepitant and palonosetron have demonstrated promising outcomes in the control of acute and delayed CINV according to previous studies. ${ }^{11-14)}$ Also, the increased dexamethasone has been previously found to be effective in both acute and delayed phases. ${ }^{5,10)}$ Aprepitant, palonosetron, or extended dexamethasone may be effective to control the delayed CINV of CDDP-TAI. Despite our limited number of patients, patients receiving aprepitant and palonosetron, or dexamethasone on days 1 and 3 in our study were well controlled in both acute and delayed phases CINV (data not shown). A prospective, controlled trial is needed to clarify CDDP-TAI CINV prophylaxis. CDDP has relatively high emetogenicity, and is listed as high risk in emetogenic classification schema. Antiemetic prophylaxis with the i.v. administration of CDDP recommended is a three-drug combination with aprepitant, a $5-\mathrm{HT}_{3}$ antagonist and dexamethasone. However, three-drug combination may be not necessary to the intra-arterial administration of CDDP since the intra-arterial administration is thought to have fewer systemic adverse effects than i.v. administration. If patients received extended dexamethasone, it is worth keeping in mind that up to $15 \%$ of hepatocellular cancer patients are infected with Hepatitis B virus (HBV). Considering that Mochida 
described how corticosteroids managed to reactivate $\mathrm{HBV}$, it may be necessary therefore to screen for existing HBV infections prior to undertaking an antiemetic prophylaxis regime that involved extended dexamethasone use. ${ }^{20)}$ The monitoring of $\mathrm{HBV}$ reactivation could be managed according to established guidelines. ${ }^{21)}$

In conclusion, the present study confirms that administration of a $5-\mathrm{HT}_{3}$ receptor antagonist and dexamethasone only on day 1 is effective for acute phase, but not delayed phase, CINV in CDDP-TAI. The development of better antiemetic prophylaxis guidelines will lead to improved treatment compliance and therapeutic outcomes.

Conflict of Interest The authors declare no conflict of interest.

\section{REFERENCES}

1) de Boer-Dennert M, de Wit R, Schmitz PI, Djontono J, v Beurden V, Stoter G, Verweij J. Patient perceptions of the side-effects of chemotherapy: the influence of $5 \mathrm{HT}_{3}$ antagonists. $\mathrm{Br}$. J. Cancer, $\mathbf{7 6}$, 1055-1061 (1997).

2) Roila F, Herrstedt J, Aapro M, Gralla RJ, Einhorn LH, Ballatori E, Bria E, Clark-Snow RA, Espersen BT, Feyer P, Grunberg SM, Hesketh PJ, Jordan K, Kris MG, Maranzano E, Molassiotis A, Morrow G, Olver I, Rapoport BL, Rittenberg C, Saito M, Tonato M, Warr D, ESMO/MASCC Guidelines Working Group. Guideline update for MASCC and ESMO in the prevention of chemotherapy- and radiotherapy-induced nausea and vomiting: results of the Perugia consensus conference. Ann. Oncol., 21 (Suppl. 5), v232-v243 (2010).

3) National Comprehensive Cancer Network. "NCCN Clinical Practice Guidelines in Oncology; Antiemetics Version 2.2014.”: 〈http://www. nccn.org/professionals/physician_gls/pdf/antiemesis.pdf), cited 22 March, 2015.

4) Basch E, Prestrud AA, Hesketh PJ, Kris MG, Feyer PC, Somerfield MR, Chesney M, Clark-Snow RA, Flaherty AM, Freundlich B, Morrow G, Rao KV, Schwartz RN, Lyman GH, American Society of Clinical Oncology. Antiemetics: American Society of Clinical Oncology clinical practice guideline update. J. Clin. Oncol., 29, 4189-4198 (2011).

5) Japan Society of Clinical Oncology. "Seitoyaku tekiseishiyou guideline.” Kanehara Shuppan, Tokyo (2010).: 〈http://www.jsco-cpg.jp/ guideline/29.html, cited 22 March, 2015.

6) Court WS, Order SE, Siegel JA, Johnson E, DeNittis AS, Principato R, Martz K, Zeiger LS. Remission and survival following monthly intraarterial cisplatinum in nonresectable hepatoma. Cancer Invest., 20, 613-625 (2002).

7) The Japan Society of Hepatology. "Evidence-based practice guideline for the treatment for hepatocellular cancer in Japan." Kanehara Shuppan, Tokyo (2013).: 〈http://www.jsh.or.jp/medical/guidelines/ jsh_guidlines/examination_jp», cited 22 March, 2015.

8) Louvet C, Lorange A, Letendre F, Beaulieu R, Pretty HM, Courchesne Y, Neemeh JA, Monte M, Latreille J. Acute and delayed emesis after cisplatin-based regimen: description and prevention. Oncology, 48, 392-396 (1991).

9) Yoshikawa M, Ono N, Yodono H, Ichida T, Nakamura H. Phase II study of hepatic arterial infusion of a fine-powder formulation of cisplatin for advanced hepatocellular carcinoma. Hepatol. Res., $\mathbf{3 8}$, 474-483 (2008).
10) Kodama Y, Higuchi N, Egashira K, Yamaguchi K, Hamamoto T, To H, Kitahara T, Sasaki H. Evaluation of antiemetic therapy for the prevention of delayed nausea and vomiting associated with cancer chemotherapy. J. Jpn. Soc. Hosp. Pharm., 45, 781-783 (2009).

11) Takahashi $T$, Hoshi E, Takagi M, Katsumata N, Kawahara M, Eguchi K. Multicenter, phase II, placebo-controlled, double-blind, randomized study of aprepitant in Japanese patients receiving highdose cisplatin. Cancer Sci., 101, 2455-2461 (2010).

12) Hesketh PJ, Grunberg SM, Gralla RJ, Warr DG, Roila F, de Wit R, Chawla SP, Carides AD, Ianus J, Elmer ME, Evans JK, Beck K, Reines S, Horgan KJ, Aprepitant Protocol 052 Study Group. The oral neurokinin-1 antagonist aprepitant for the prevention of chemotherapy-induced nausea and vomiting: a multinational, randomized, double-blind, placebo-controlled trial in patients receiving high-dose cisplatin - the Aprepitant Protocol 052 Study Group. J. Clin. Oncol., 21, 4112-4119 (2003).

13) Warr DG, Hesketh PJ, Gralla RJ, Muss HB, Herrstedt J, Eisenberg PD, Raftopoulos H, Grunberg SM, Gabriel M, Rodgers A, Bohidar N, Klinger G, Hustad CM, Horgan KJ, Skobieranda F. Efficacy and tolerability of aprepitant for the prevention of chemotherapy-induced nausea and vomiting in patients with breast cancer after moderately emetogenic chemotherapy. J. Clin. Oncol., 23, 2822-2830 (2005).

14) Saito M, Aogi K, Sekine I, Yoshizawa H, Yanagita Y, Sakai H, Inoue K, Kitagawa C, Ogura T, Mitsuhashi S. Palonosetron plus dexamethasone versus granisetron plus dexamethasone for prevention of nausea and vomiting during chemotherapy: a double-blind, double-dummy, randomised, comparative phase III trial. Lancet Oncol., 10, 115-124 (2009).

15) Torii Pharmaceutical Co. Ltd. "Serotone (azasetron) Package Insert (2011).”: 〈http://www.info.pmda.go.jp/go/pack/2391402A1039_1_04/>, cited 22 March, 2015.

16) Jordan K, Hinke A, Grothey A, Voigt W, Arnold D, Wolf HH, Schmoll HJ. A meta-analysis comparing the efficacy of four $5-\mathrm{HT}_{3}-$ receptor antagonists for acute chemotherapy-induced emesis. Support. Care Cancer, 15, 1023-1033 (2007).

17) Honda S, Miyahara Y, Yoshimura M, Ohno K, Meguro Y, Mimashu $\mathrm{S}$, Imagawa F. Comparative study of intravenous doses of granisetron during moderately emetogenic chemotherapy. J. Jpn. Soc. Hosp. Pharm., 48, 169-172 (2012).

18) Motohashi S, Hori K, Ono T, Ohnishi K, Kawakami J. Comparison of $1 \mathrm{mg} /$ body and $3 \mathrm{mg} /$ body of intravenous granisetron for the prevention of chemotherapy-induced nausea and vomiting and adverse events in hematological malignancy patients. Yakugaku Zasshi, 132, 675-681 (2012).

19) Matsumura T, Arai M, Yoshikawa M, Sudo K, Nakamura K, Katsuno T, Kanai F, Yamaguchi T, Yokosuka O. Changes in plasma ghrelin and serum leptin levels after Cisplatin-based transcatheter arterial infusion chemotherapy for hepatocellular carcinoma. ISRN Gastroenterol., 2013, 415450 (2013). doi: 10.1155/2013/415450

20) Mochida T. "HBV Reactivation through Immunosuppressive and/or Anti-cancer Therapies Research Group. HBV Reactivation through immunosuppressive and/or anti-cancer therapies, elucidation and establishment of countermeasures." The Japanese Ministry of Health, Labour and Welfare (2012).: 〈http://mhlw-grants.niph.go.jp/ niph/search/NIDD00.do?resrchNum=201125002A), cited 22 March, 2015.

21) Drafting Committee for Hepatitis Management Guidelines, the Japan Society of Hepatology. JSH Guidelines for the Management of Hepatitis B Virus Infection. Hepatol. Res., 44 (Suppl. S1), 1-58 (2014). 